\title{
Impact of meteorological parameters on COVID-19 transmission in Bangladesh: a spatiotemporal approach
}

\author{
Al-Ekram Elahee Hridoy ${ }^{1}$. Md. Abdul Mohiman ${ }^{1} \cdot$ Shekh Md. Shajid Hasan Tusher ${ }^{1} \cdot$ Sayed Ziaul Amin Nowraj ${ }^{1}$. \\ Mohammad Atiqur Rahman ${ }^{1}$ (D)
}

Received: 14 December 2020 / Accepted: 11 January 2021 / Published online: 3 February 2021

(C) The Author(s), under exclusive licence to Springer-Verlag GmbH, AT part of Springer Nature 2021

\begin{abstract}
It has been more than 10 months since the first COVID-19 case was reported in Wuhan, China, still menacing the world with a possible second wave. This study aimed to analyze how meteorological variables can affect the spread of local COVID-19 transmission in Bangladesh. Nine spatial units were considered from a meteorological standpoint to characterize COVID-19 transmission in Bangladesh. The daily COVID-19 incidence and meteorological variable (e.g., mean temperature, relative humidity, precipitation, and wind speed) data from April 5 to September 20, 2020, were collected. The Spearman rank correlation, heat maps, and multivariate quasi-Poisson regression were employed to understand their association. The effect of meteorological variables on COVID-19 transmission was modeled using a lag period of 10 days. Results showed that mean temperature, relative humidity, and wind speed are substantially associated with an increased risk of COVID-19. On the other hand, daily precipitation is significantly associated with a decreased risk of COVID-19 incidence. The relative risks (RR) of mean temperature for daily COVID-19 incidences were 1.222 (95\% confidence interval [CI], 1.214-1.232). For wind speed, the RR was 1.087 (95\% CI, 1.083-1.090). For relative humidity, the RR was 1.027 (95\% CI, 1.025-1.029). Overall, this study found the profound effect of meteorological parameters on COVID-19 incidence across selected nine areas in Bangladesh. This study is probably the first study to explore the impact of region-specific meteorological conditions on COVID-19 incidence in Bangladesh. Moreover, adjustments on the areal-aggregated and regional levels were made for three confounding factors, including lockdown, population density, and potential seasonal effects. The study's findings suggest that SARS-CoV-2 can be transmitted in high temperatures and humidity conditions, which contradicts many other countries' prior studies. The research outcomes will provide implications for future control and prevention measures in Bangladesh and other countries with similar climate conditions and population density.
\end{abstract}

Mohammad Atiqur Rahman

mmd.atiqur.rahman@cu.ac.bd

Al-Ekram Elahee Hridoy aliqramalaheehridoy@gmail.com

Md. Abdul Mohiman

ma.mohiman.cu@gmail.com

Shekh Md. Shajid Hasan Tusher shajidtushergeo@gmail.com

Sayed Ziaul Amin Nowraj sayednowraj@gmail.com

1 Department of Geography and Environmental Studies, University of Chittagong, Chittagong 4331, Bangladesh

\section{Introduction}

The ripple effect of the SARS-CoV-2 pathogen has caused unprecedented havoc to humans and economies. The current corona virus (COVID-19) disease, caused by SARS-CoV-2 pathogen, first came to attention in a cluster of cases with atypical pneumonia cases in Hubei province, China. The virus rapidly broke out within China and continued to spread all over the world. Since then, enormous efforts have been taken to contain virus transmission; nonetheless, the disease continued to spread globally. On March 11, 2020, the World Health Organization (WHO) declared COVID-19 as a global pandemic (WHO 2020).

Multiple factors can influence the transmission of corona viruses including climatic conditions, geographical factors, population density, and other social factors (Dalziel et al. 2018; Liu et al. 2020). A plethora of studies have indicated 
that during cold and low humidity conditions, the respiratory infection was enhanced unusually, indicating low temperature and low humidity might significantly contribute to the transmission and survival of the corona viruses (Davis et al. 2016; Rendana 2020; Wang et al. 2020). Several studies (Cai et al. 2007; Casanova et al. 2010; Shi et al. 2020) emphasized that environmental factors may affect corona virus viability through its transmission routes. Several retrospect studies have revealed that temperature and humidity might have affected the SARS outbreak and gradually faded away with warmer weather conditions (Cao et al. 2016; Liu et al. 2020; Tan et al. 2005). Similar to SARS, epidemiological studies have revealed that droplet-mediated viral diseases like influenza have also shown sensitivity to meteorological factors. This finding indicates that cold-dry weather condition is aiding for its survival and propagation (Lowen et al. 2007; Shaman and Kohn 2009; Wang et al. 2020). It has been speculated that climatic conditions might slow down the transmission of COVID-19, as happened with influenza (Briz-Redón and Serrano-Aroca 2020; Shaman and Kohn 2009) and preliminary evidence from other corona viruses (Briz-Redón and Serrano-Aroca 2020).

The association between meteorological factors and SARS-CoV-2 transmission has been investigated by many studies throughout the world (O'Reilly et al. 2020; Oliveiros et al. 2020; Sajadi et al. 2020; Shi et al. 2020; Wei et al. 2020). Among the meteorological factors, temperature, humidity, wind speed, and precipitation are considered to be crucial meteorological factors in predicting COVID-19 transmission (Zhang et al. 2020). Therefore, it is imperative to explore the potential effects of weather variability on the spread and viability of the SARS-CoV-2 (Xie and Zhu 2020; Zhang et al. 2020).

Bangladesh is one of the world's most populous countries with a subtropical monsoon climate. Therefore, the complex interrelation between meteorological variables, poverty, and high population density exists, implying a higher level of exposure to COVID-19. However, studies related to the association between local meteorological variables and local-level COVID-19 transmission in Bangladesh are scarce. The association between meteorological factors and the COVID-19 outbreak has been investigated by several studies (Haque and Rahman 2020; Hasan and Siddik 2020; Mofijur et al. 2020). However, these studies have been limited in several ways; study areas are geographically limited, mainly concentrated in Dhaka city and its peripheries. Though Haque and Rahman et al. (2020) used nationwide COVID-19 data, the meteorological datasets were only of Dhaka city, without accounting for the whole country's daily weather variation. Moreover, the authors mostly used simpler approaches such as descriptive statistics, basic correlation coefficient, or simple regression analysis. However, simpler approaches do not account for heterogeneity in the datasets, which can reduce the reliability of the findings (Briz-Redón and Serrano-Aroca 2020). Additionally, most of these studies have performed analyses without accounting for latent periods of COVID-19 and potential confounding factors. For these reasons, the findings of those studies might be biased. However, in a recent study using a distributed log nonlinear model (DLNM), Islam et al. $(2020 \mathrm{a}, \mathrm{b})$ found that temperature, relative humidity, and wind speed are positively associated with the spread of SARSCoV-2 in Bangladesh.

The impacts of environmental drivers on COVID-19 might be heavily confounded by population density, immunity, nonpharmaceutical interventions, human behavior, economy, and other factors. Considering several potential confounding factors, Lin et al. (2013) have investigated the potential effects of environmental factors on the SARS epidemic in Hong Kong. If these factors are not considered when assessing the potential impact of meteorological variables on COVID-19 transmission, the result can lead to spurious conclusions. Jahangiri et al. (2020) have also mentioned that the transmission of COVID-19 has a high sensitivity to population size.

The Government of Bangladesh imposed only 66 days (from March 26, 2020, to May 30, 2020) nationwide lockdown. Intervention measures are likely to impact the spread of the virus significantly. Thus, public health intervention could be a major potential confounding factor in assessing the impacts of meteorological variables in Bangladesh, which needs to be considered. All these factors are needed to be considered while exploring the role of meteorology on COVID-19 occurrence in Bangladesh, since the spatial and temporal heterogeneities in COVID-19 incidence could be attributed to meteorological variables as well as intervention measures across regions (Wang and Du 2020).

This research aims to identify the potential role of meteorological variables on COVID-19 transmission in Bangladesh in two approaches: firstly, potential impacts of meteorological variables on daily COVID-19 incidence and, secondly, the association between effective reproduction number (Rt) and meteorological variables followed by Guo et al. (2020), Poirier et al. (2020), and $\mathrm{Yu}$ (2020). Though a good number of studies have explored the relationship of COVID-19 and air quality (Rahman et al. 2020), with meteorological parameters (Islam et al. 2020b), socio-economic factors (Shammi et al. 2020a), and lockdown scenarios (Shammi et al. 2020b) in Bangladesh, however, this research aimed to explore how meteorological parameters can mediate SARS-CoV-2 transmission at community level. Therefore, present research focused on region-specific climate impacts on local COVID-19 transmission expanding observation period, considering population density, lockdown, and potential seasonal effects. Thus, the result might provide better insights. The research results might be of interest to policy makers, academics, and citizens. Authors hope understanding the research outcomes might assist policy makers to prepare a better response 
mechanism for Bangladesh perspective. Moreover, it will be an essential reference for advanced research to quantify how local-level meteorological factors can impact on viral disease transmission.

\section{Data and methods}

\subsection{Study area}

Bangladesh has a humid subtropical climate with wide seasonal rainfall variations, moderately warm temperatures, and high humidity. The study areas are carefully chosen based on their spatial position with varying population sizes and densities. Besides, therapeutic measures, environmental factors, and population sizes are also essential measures for epidemiological study (Dalziel et al. 2018; Hemmes et al. 1960; Liu et al. 2020). The study areas include both high and sparsely populated districts (Fig. 1). Yuan et al. (2020) have mentioned that numbers of infected people in concentrated and sporadic outbreak areas are dissimilar. A recent symposium convened by the World Meteorological Organization (WMO) suggested that studies should attempt to model spatially and temporally align epidemiological and meteorological data (Zaitchik et al. 2020). Therefore, it will be appropriate to include both concentrated and sporadic outbreak areas while exploring meteorological impacts on COVID-19. Besides, these selected regions are meteorologically representative of the seven climate zones of Bangladesh (Rashid 2019). Additionally, these areas are the lifeline of Bangladesh, playing essential roles in national life. Moreover, these include the capital city, the largest port city, industrial parks, specialized economic zones, and business hub. Additionally, few areas (Dhaka city, Narayanganj, and Gazipur) were the initial epicenter of COVID-19.

\subsection{Data sources}

Daily counts of laboratory-confirmed cases (if confirmed, cumulative cases are $\geq 2$ in each area) and weather variable data

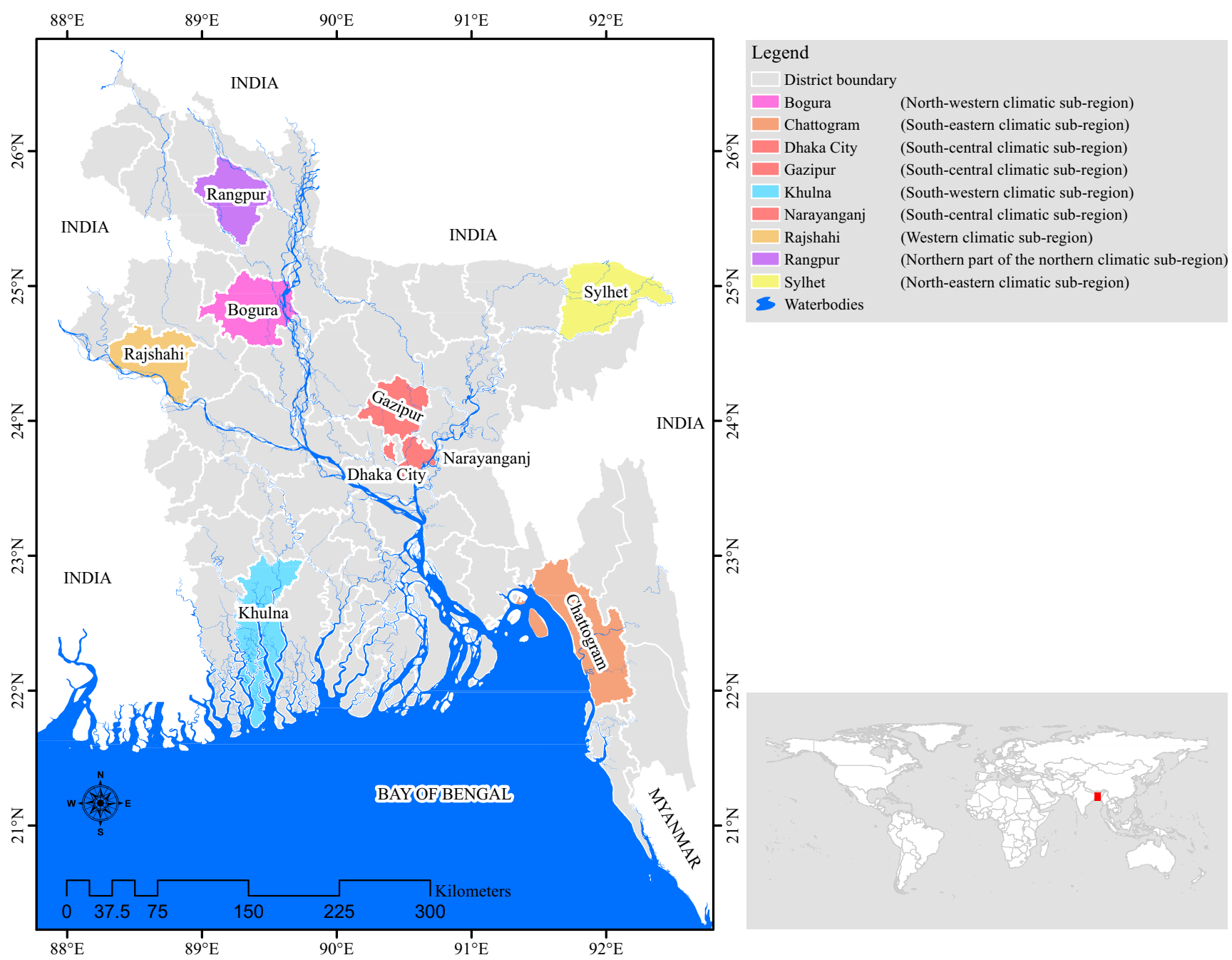

Fig. 1 Selected areas from seven climatic zones of Bangladesh 
were collected from April 5, 2020, to September 20, 2020 (169 days).

A longer time series data of meteorological variables may reveal a more accurate impact of meteorological variables on the COVID-19 local transmission. Moreover, two weather seasons, namely a hot humid summer (April to May) and rainy monsoon (June to September), overlapped during the study period. This overlapped study period will help to account large band of meteorological parameters. The meteorological variables that have been considered for this study are daily average temperature $\left({ }^{\circ} \mathrm{C}\right)$, relative humidity $(\%)$, precipitation $(\mathrm{mm})$, and wind speed $(\mathrm{km} / \mathrm{h})$. The daily confirmed positive COVID-19 cases were collected from the Institute of Epidemiology, Disease Control and Research (IEDCR), and meteorological data were collected from National Oceanic and Atmospheric Administration (NOAA) daily global data. The population density data were obtained from the Bangladesh Bureau of Statistics (BBS) (BBS 2011).

\subsection{Heat map}

The association between local daily COVID incidence and meteorological variables were examined using a heat map. The daily new incidences were transformed into a logarithmic scale using $\log (N+1)$ to improve the contrast. The heat map could identify the range of optimal meteorological threshold for local transmissions (Runkle et al. 2020). The weather data is lagged by 10 days based on the assumed incubation period of COVID-19.

\subsection{Quasi-Poisson model}

Since COVID-19 data is a discrete count variable, modeling the association between weather variables and daily confirmed cases with linear regression could result in inconsistent and biased estimation (Briz-Redón and Serrano-Aroca 2020; Hoffmann 2004; Long 1997). Moreover, a linear regression model with Gaussian errors can estimate negative predicted values. The standard and alternative to linear regression for the count variable is Poisson regression. The Poisson regression is a form of the generalized linear model. The Poisson regression assumes that the count follows Poisson distribution, assuming that variance is equal to the mean. However, infectious disease counts often have a variance above expected in a Poisson distribution (Imai et al. 2015), and overdispersion occurs in the datasets. The quasi-Poisson regression is a generalized form of the Poisson regression and a standard model for modeling an overdispersed count variable.

A generalized linear model (GLM) with a quasi-Poisson regression had given the best fit for overdispersed disease case data and meteorological variables (Joshi et al. 2016; Lin et al. 2013). Thus, accounting for the data dispersion, this study adopted a log-linear quasi-Poisson regression model to estimate the association between climate variables and daily counts of confirmed cases at the district level and to evaluate the variance explained by meteorological parameters for outcome variable daily COVID-19 counts (Imai et al. 2015).

In the quasi-Poisson model, the variance is scaled by a constant dispersion parameter $\left(\sigma^{2}\right)$. Thus, the model can be written as follows:

$$
\begin{gathered}
y \mid \eta \sim \operatorname{Po}\left(\mu \sigma^{2}\right) \\
\left.\log (u)=\eta=\beta_{0}+\beta_{1}\left(t_{\text {mean }}\right)+\beta_{2}(\text { humidity })+\beta_{3} \text { (precipitation }\right) \\
+\beta_{4}(\text { wind speed })+\text { DOW }+ \text { Lockdown }+ \text { COV }
\end{gathered}
$$

where $y$ represents the expected number of daily counts, $\eta$ is the fitted model, Po represents the Poisson distribution, $\beta_{0}$ is the overall coefficient, and $\beta_{1}, \beta_{2}, \beta_{3}$, and $\beta_{4}$ are coefficients for mean temperature $\left({ }^{\circ} \mathrm{C}\right)$, relative humidity $(\%)$, precipitation $(\mathrm{mm})$, and wind speed $(\mathrm{km} / \mathrm{h})$ respectively. DOW is a categorical variable indicating the day of the week to account for any potential seasonal effects or time-varying trend. Lockdown is a dummy variable set to 1 if a day is among the lockdown days; 0 otherwise. $\mathrm{COV}$ is the log of population density of each region set as an offset to the model to account for the regional-level heterogeneity. When we employed region-specific regression analysis, we did not consider population density as a potential confounding factor. Within one community or population throughout our study period, targeted population does not change over time (Imai and Hashizume 2014; Rothman et al. 2008). One confounding factor could be the daily number of tests performed districtwise. Unfortunately, district-wise COVID-19 testing data are scarce (New Age 2020). Thus, we excluded district-wise testing data as a potential confounder. A recent study reported that the mean incubation period of COVID-19 varies from 8 to 14 days (Qin et al. 2020). Thus, we considered the cumulative lag effects of weather conditions on COVID-19 cases. The meteorological variables were analyzed using 10-day moving average based on the assumed incubation period of COVID19. We carried out all analyses in R statistical software version 3.6.3, graphical presentation in ArcGIS 10.8 and Python 3.

\section{Result}

\subsection{Descriptive statistics}

Figure 2 presents the dynamics of COVID-19 in the selected study areas. Dhaka city has registered the highest number of new daily cases, mainly from mid-April onwards, when the number of confirmed cases exhibited significant increases. The other areas have the following order of occurrence of new COVID-19 cases from April 5, 2020, to September 20, 2020: Chattogram $>$ Narayanganj $>$ Gazipur $>$ Khulna $>$ Bogura $>$ Sylhet $>$ Rangpur $>$ Rajshahi. The highest number 


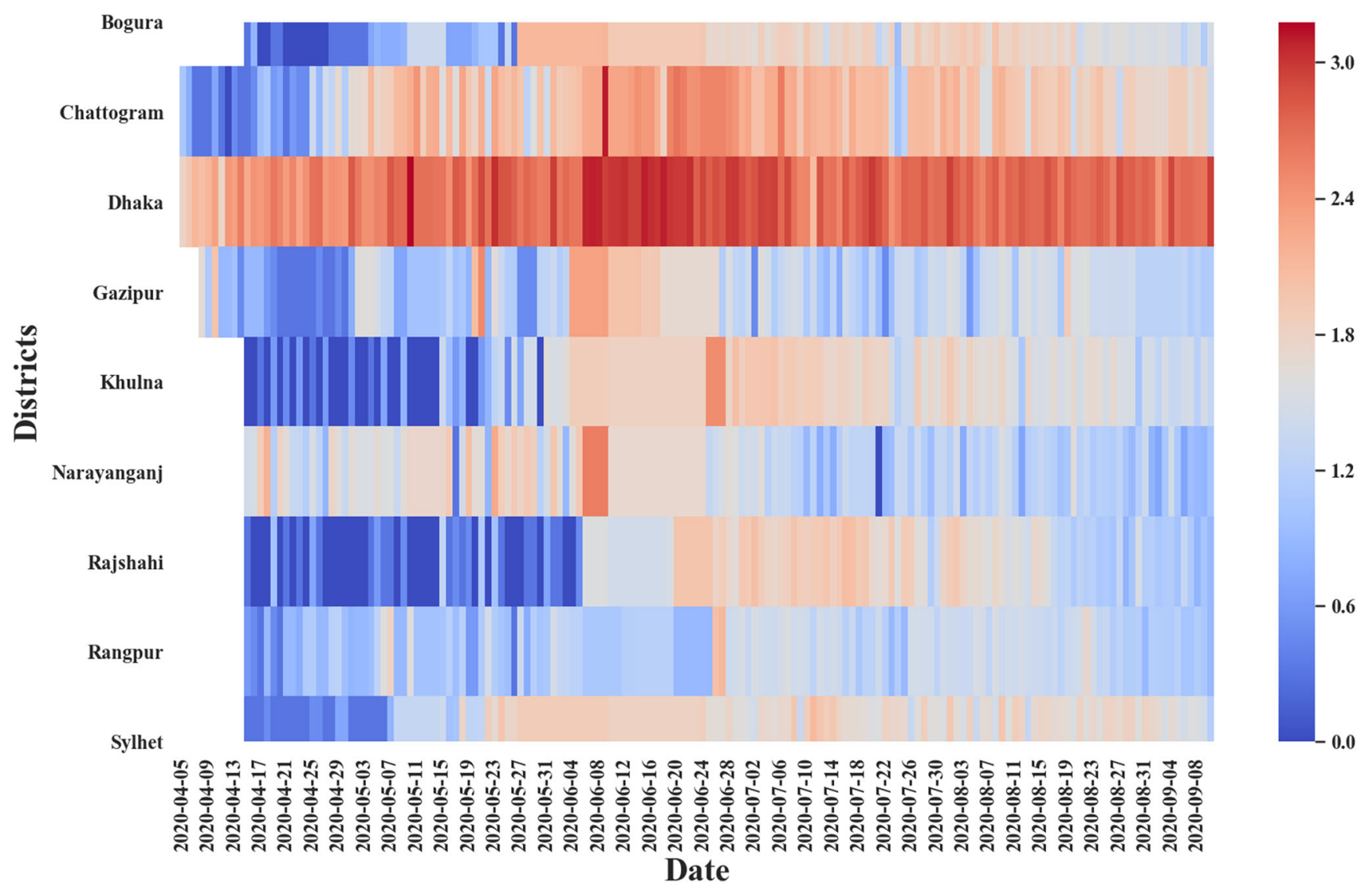

Fig. 2 The dynamics of COVID-19 in the selected areas of Bangladesh

of COVID-19 cases for Dhaka, Chattogram, Narayanganj, and Gazipur is related to these cities' importance. These cities are the main economic hub for job seekers and the country's most densely populated cities. Jahangiri et al. (2020) have recently mentioned that the population size significantly regulates the spread rate of COVID-19. Considering their economic relevance and high population density, these cities deserve special attention to analyze the evolution of COVID-19 cases.

Table 1 depicts a statistical summary of meteorological distribution in selected areas. The wide variation is observed as they pertain to seven climatic zones of Bangladesh. The temperature ranged from a minimum of $20.90{ }^{\circ} \mathrm{C}$ to a maximum of $33.30{ }^{\circ} \mathrm{C}$. The highest relative humidity, $98.00 \%$, is recorded in Sylhet, Dhaka, and its two peripheral districts, while the lowest relative humidity $(50.00 \pm 8.58 \%)$ is also observed in Dhaka city. Precipitation comparatively exhibits high variations among districts; Rangpur received maximum precipitation of $249.68 \mathrm{~mm}$. The highest magnitude of wind speed $(25.4 \mathrm{~km} / \mathrm{h})$ is recorded in Rangpur. Dhaka city has the highest confirmed cases, followed by Chattogram. Minimum cases have been registered in Rangpur.

Table 2 summarizes monthly variations of the weather variables and new cases in Bangladesh. Average new cases show a continuous rapid increment trend from April to June. After that, a slow downward trend is observed. Temperature showed a consistently increasing trend from April $\left(26.84 \pm 2.12{ }^{\circ} \mathrm{C}\right)$ to September $\left(29.59 \pm 1.35{ }^{\circ} \mathrm{C}\right)$ except for a slight variation in July. Relative humidity has also followed a continuous increment trend from April $(76.27 \pm 8.40 \%)$ to July $(85.90 \pm 5.70 \%)$. Precipitation has shown a rising trend from April $(7.33 \mathrm{~mm})$ to July $(16.64 \mathrm{~mm})$ before taking a downturn. Wind speed exhibits comparatively less variation within the study period. The highest wind speed was detected in May $(4.95 \mathrm{~km} / \mathrm{h})$; after that, a continuous decreasing trend except for August. The lowest wind speed is observed in September $(3.15 \mathrm{~km} / \mathrm{h})$.

The Spearman rank correlation (Table 3) suggests a significant but weak correlation between COVID-19 new cases and meteorological variables.

Mean temperature exhibited a weak and significant positive correlation with daily COVID-19 incidence for all districts except Narayanganj.

Like temperature, relative humidity exhibited a weak and significant positive correlation with daily COVID-19 incidence for all districts except for Bogura and Gazipur. In contrast, a significant weak negative association was detected for Narayanganj.

Precipitation exhibited a significantly weak positive correlation with COVID-19 incidence for Dhaka, Chattogram, Rangpur, and Rajshahi. 
Table 1 Descriptive analysis of the meteorological variables and daily new cases of selected areas (April 5-September 20, 2020)

\begin{tabular}{|c|c|c|c|c|c|}
\hline Statistics & New daily cases & Temperature $\left({ }^{\circ} \mathrm{C}\right)$ & Relative humidity (\%) & Precipitation (mm) & Wind speed $(\mathrm{km} / \mathrm{h})$ \\
\hline \multicolumn{6}{|l|}{ Dhaka city } \\
\hline Mean & 536.76 & 29.16 & 80.64 & 8.73 & 3.64 \\
\hline Minimum & 10.00 & 23.70 & 50.00 & 0.00 & 0.00 \\
\hline Maximum & 1508.00 & 32.30 & 98.00 & 89.15 & 16.10 \\
\hline Standard deviation & 298.28 & 1.68 & 8.58 & 15.73 & 2.19 \\
\hline \multicolumn{6}{|l|}{ Chattogram District } \\
\hline Mean & 109.76 & 29.30 & 79.20 & 12.08 & 5.46 \\
\hline Minimum & 0.00 & 25.28 & 56.91 & 0.00 & 0.34 \\
\hline Maximum & 1289.00 & 31.88 & 96.33 & 102.11 & 12.37 \\
\hline Standard deviation & 131.26 & 1.33 & 7.60 & 18.96 & 2.15 \\
\hline \multicolumn{6}{|l|}{ Narayanganj District } \\
\hline Mean & 40.92 & 29.13 & 81.78 & 9.26 & 3.69 \\
\hline Minimum & 0.00 & 23.70 & 62.00 & 0.00 & 0.00 \\
\hline Maximum & 379.00 & 32.30 & 98.00 & 89.15 & 16.10 \\
\hline Standard deviation & 60.50 & 1.67 & 7.18 & 16.07 & 2.21 \\
\hline \multicolumn{6}{|l|}{ Gazipur District } \\
\hline Mean & 32.13 & 29.13 & 81.09 & 8.88 & 3.66 \\
\hline Minimum & 1.00 & 23.70 & 58.00 & 0.00 & 0.00 \\
\hline Maximum & 315.00 & 32.30 & 98.00 & 89.15 & 16.10 \\
\hline Standard deviation & 47.19 & 1.67 & 7.91 & 15.83 & 2.20 \\
\hline \multicolumn{6}{|l|}{ Sylhet District } \\
\hline Mean & 41.59 & 27.70 & 84.59 & 21.81 & 4.27 \\
\hline Minimum & 1 & 20.90 & 63.00 & 0.00 & 0.70 \\
\hline Maximum & 122 & 32.30 & 98.00 & 171.20 & 13.10 \\
\hline Standard deviation & 28.00 & 1.94 & 7.95 & 27.66 & 2.33 \\
\hline \multicolumn{6}{|l|}{ Rangpur District } \\
\hline Mean & 17.11 & 28.31 & 83.23 & 14.59 & 2.58 \\
\hline Minimum & 1.00 & 22.20 & 65.00 & 0.00 & 0.00 \\
\hline Maximum & 128.00 & 32.30 & 95.00 & 249.68 & 25.40 \\
\hline Standard deviation & 15.30 & 2.06 & 6.48 & 28.77 & 2.22 \\
\hline \multicolumn{6}{|l|}{ Rajshahi District } \\
\hline Mean & 29.29 & 29.07 & 84.28 & 7.49 & 3.71 \\
\hline Minimum & 0.00 & 23.60 & 65.00 & 0.00 & 0.70 \\
\hline Maximum & 115.00 & 32.00 & 96.00 & 77.22 & 21.10 \\
\hline Standard deviation & 32.41 & 1.79 & 6.33 & 13.86 & 2.21 \\
\hline \multicolumn{6}{|l|}{ Bogura District } \\
\hline Mean & 46.04 & 28.80 & 82.42 & 11.28 & 3.37 \\
\hline Minimum & 0.00 & 23.00 & 64.00 & 0.00 & 0.40 \\
\hline Maximum & 139.00 & 32.60 & 96.00 & 101.85 & 9.60 \\
\hline Standard deviation & 38.70 & 1.98 & 6.20 & 20.73 & 1.64 \\
\hline \multicolumn{6}{|l|}{ Khulna District } \\
\hline Mean & 39.92 & 29.44 & 81.62 & 8.12 & 2.86 \\
\hline Minimum & 0.00 & 24.40 & 66.00 & 0.00 & 0.00 \\
\hline Maximum & 303.00 & 33.30 & 94.00 & 79.50 & 25.00 \\
\hline Standard deviation & 46.61 & 1.64 & 6.88 & 13.90 & 2.85 \\
\hline
\end{tabular}


Table 2 Monthly changes in the COVID-19 and meteorological variables (mean $\pm \mathrm{SD}$ ) in the selected areas

\begin{tabular}{|c|c|c|c|c|c|c|c|c|c|c|c|c|}
\hline \multirow[t]{2}{*}{ Variables } & \multicolumn{2}{|l|}{ April } & \multicolumn{2}{|l|}{ May } & \multicolumn{2}{|l|}{ June } & \multicolumn{2}{|l|}{ July } & \multicolumn{2}{|c|}{ August } & \multicolumn{2}{|c|}{ September } \\
\hline & Mean & SD & Mean & SD & Mean & SD & Mean & SD & Mean & SD & Mean & SD \\
\hline New daily cases & 29.47 & 70.26 & 69.24 & 162.02 & 159.20 & 275.75 & 137.81 & 216.80 & 97.74 & 161.77 & 85.70 & 170.92 \\
\hline Temperature $\left({ }^{\circ} \mathrm{C}\right)$ & 26.84 & 2.12 & 28.38 & 2.14 & 29.28 & 1.32 & 29.17 & 1.30 & 29.55 & 1.33 & 29.59 & 1.35 \\
\hline Relative humidity (\%) & 76.27 & 8.40 & 78.85 & 7.68 & 82.89 & 6.34 & 85.90 & 5.70 & 84.12 & 5.84 & 82.59 & 6.64 \\
\hline Precipitation $(\mathrm{mm})$ & 7.33 & 15.23 & 10.90 & 21.85 & 11.88 & 18.84 & 16.64 & 26.18 & 9.58 & 14.02 & 9.23 & 18.84 \\
\hline Wind speed $(\mathrm{km} / \mathrm{h})$ & 4.23 & 2.93 & 4.95 & 4.42 & 4.52 & 3.47 & 4.48 & 3.91 & 4.85 & 4.30 & 3.15 & 2.79 \\
\hline
\end{tabular}

Wind speed was very weak and significantly correlated with COVID-19 incidence for Chattogram and Khulna.

\subsection{Heat maps}

The association between local daily COVID incidence and meteorological variables was examined using a heat map. The heat map (Fig. 3) reveals that the association between meteorological variables and COVID-19 incidence varied spatially. However, the COVID-19 incidence was common in high temperatures $\left(28-31^{\circ} \mathrm{C}\right)$ and with daily rainfall $(0$ $44 \mathrm{~mm}$ ) conditions for all areas. A higher number of cases were reported in all areas with a high humidity range (80$94 \%$ ). Similarly, a higher number of cases were reported in all areas with low wind speed $(0-5 \mathrm{~km} / \mathrm{h})$. However, a higher number of cases were also reported in Chattogram, with high wind speed $(14-25 \mathrm{~km} / \mathrm{h})$.

\subsection{Effect of meteorological variables on daily COVID- 19 incidence}

Multivariate quasi-Poisson regression was used to evaluate the daily COVID-19 incidence association with meteorological variables in each area (Table 4).

In Dhaka, the initial epicenter of the outbreak, mean temperature and wind speed were strongly associated with increased risk of daily COVID-19 incidence. Mean temperature significantly affected the increased risk of COVID-19 incidence (RR 1.128; 95\%, CI 1.127-1.150). Wind speed also exhibited a significant positive association with COVID-19 incidence (RR, 1.062; 95\% CI, 1.056-1.068).

In Chattogram, temperature, relative humidity, and precipitation were significantly associated with increased daily COVID-19 incidence. Mean temperature was a significant effector on case increase (RR, 1.952; 95\% CI, 1.885-2.023). Relative humidity also exhibited a strong positive association with COVID-19 incidence (RR, 1.188; 95\% CI 1.105-1.133). Precipitation also exhibited a positive association with COVID-19 incidence (RR, 1.033; 95\% CI, 1.030-1.036).

In Narayanganj, increased relative humidity was significantly associated with decreased risk of daily COVID-19 incidence (RR, 0.897; 95\% CI, 0.888-0.905).

In Gazipur, no meteorological variables were significantly associated with daily COVID-19 incidence.

In Sylhet, all meteorological variables were significantly associated with daily COVID-19 incidence. Among the variables, increased temperature (RR, 1.129; 95\% CI, 1.084 1.177), relative humidity ( $R R, 1.099 ; 95 \% \mathrm{CI}, 1.082-1.1185$ ), and wind speed (RR, 1.224; 95\% CI, 1.181-1.269) had a positive association with increased risk of daily COVID-19 incidence, while precipitation (RR, 0.985; 95\% CI, 0.982-0.989) exhibited a negative association with daily COVID-19 incidence.
Table 3 Spearman's rank correlation coefficient between daily cases and meteorological variables of the study areas

\begin{tabular}{llccc}
\hline & Temperature & Relative humidity & Precipitation & Wind speed \\
\hline Dhaka city & $0.19^{* * *}$ & $0.23^{* * *}$ & $0.11^{* *}$ & 0.07 \\
Chattogram & $0.14 * * *$ & $0.19^{* * *}$ & $0.03 * *$ & $0.09 * * *$ \\
Gazipur & $0.10^{* * *}$ & 0.03 & 0.05 & 0.05 \\
Narayanganj & 0.10 & $-0.2 * * *$ & -0.08 & -0.07 \\
Rangpur & $0.13^{* * *}$ & $0.17^{* * *}$ & $0.03 * *$ & -0.09 \\
Sylhet & $0.28^{* *}$ & $0.43^{* * *}$ & -0.00 & -0.24 \\
Bogura & $0.40^{* * *}$ & 0.08 & 0.09 & 0.01 \\
Rajshahi & $0.37 * * *$ & $0.31^{* * *}$ & $0.17 * *$ & 0.12 \\
Khulna & $0.23 * * *$ & $0.19^{* * *}$ & -0.10 & $0.05^{* *}$ \\
\hline
\end{tabular}

$* * *$ and $* *$ indicate significance level at $1 \%$ and $5 \%$ respectively 

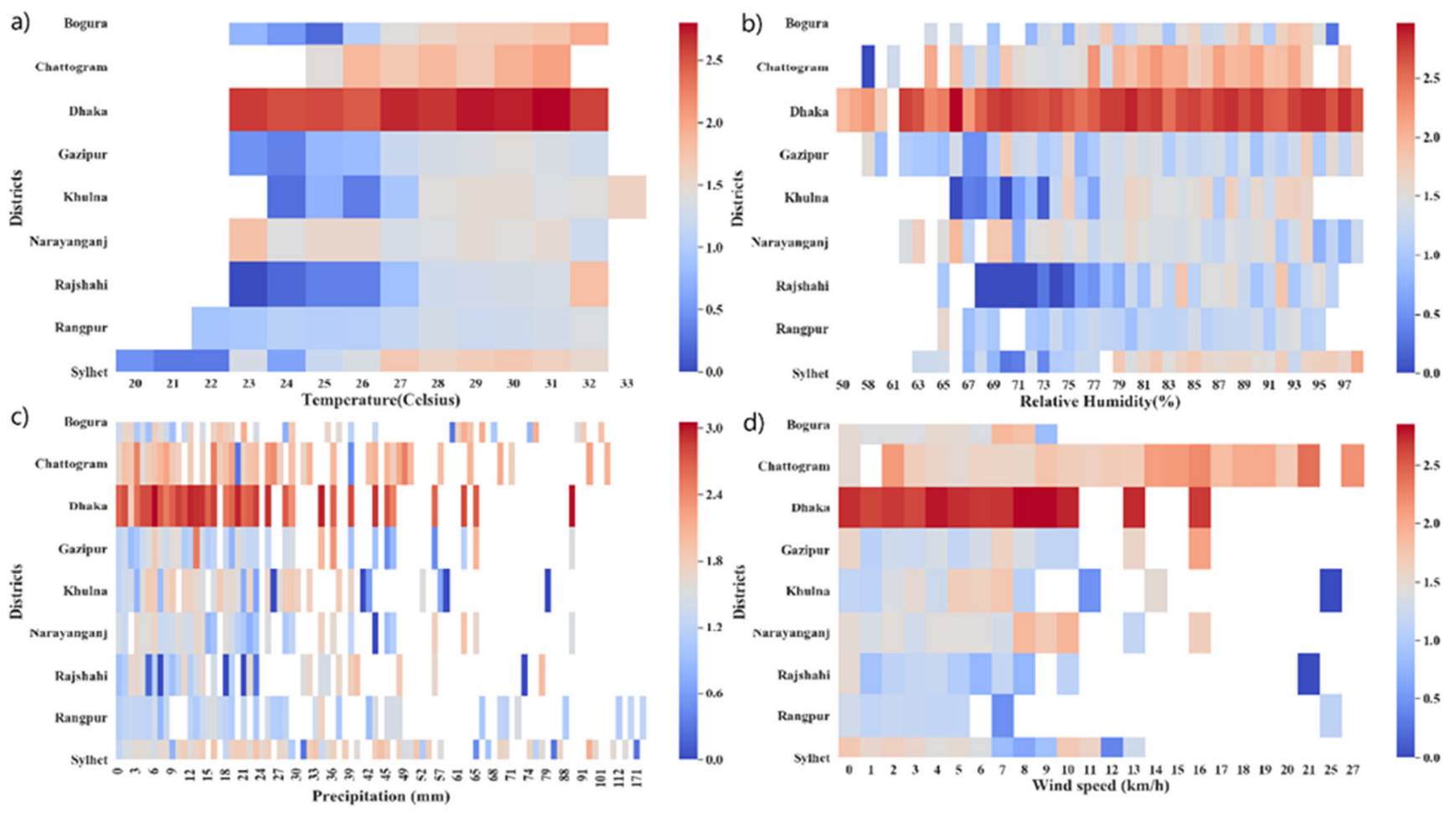

Fig. 3 The heat maps of COVID-19 cases in the selected areas in association with meteorological variables at 10-day time lag

In Rangpur, the temperature was significantly associated with increased risk of daily COVID-19 incidence (RR, 1.293 ; 95\% CI, 1.225-1.366).

In Khulna, all meteorological variables except precipitation were significantly associated with increased risk of daily COVID-19 incidence. Temperature exhibited a stronger significant effect on daily incidence (RR, 2.072; 95\% CI, 1.9112.245). Relative humidity (RR, 1.203; 95\% CI, 1.182-1.225) and wind speed (RR, 1.206; 95\% CI, 1.173-1.241) were significantly associated with increased daily COVID-19 incidence, while precipitation was negatively associated with increased risk of daily COVID-19 incidence (RR, 0.963; $95 \%$ CI, 0.955-0.971).

In Rajshahi, all meteorological variables except wind speed were significantly associated with an increased risk of daily COVID-19 incidence. Among them, temperature exhibited the highest significant effect on incidence increase (RR, 2.356; 95\% CI, 2.153-2.580). Relative humidity (RR, 1.229; 95\% CI, 1.200-1.258) and rainfall (RR, 1.044; 95\% CI, $1.037-1.0512)$ were significantly associated with increased risk of daily COVID-19 incidence.

In Bogura, all meteorological variables except relative humidity were also significantly and positively associated with daily COVID-19 incidence. Temperature (RR, 1.525; 95\% CI, 1.456-1.598), precipitation (RR, 1.047 ; $95 \%$ CI, $1.042-$ 1.052), and wind speed (RR, 1.202; 95\% CI, 1.156-1.252) were associated with increased risk of daily COVID-19 incidence.
Areal-aggregated results suggest that all meteorological variables were also significantly associated with daily COVID-19 incidence. Among them, temperature exhibited the highest significant effect on incidence increase (RR, $1.222 ; 95 \%$ CI, 1.214-1.232). Relative humidity (RR, 1.027; 95\% CI, 1.025-1.029) and wind speed (RR, 1.087; 95\% CI, $1.083-1.090$ ) were significantly associated with increased risk of daily COVID-19 incidence. In contrast, precipitation (RR, 0.989 ; 95\% CI, 0.988-0.990) was negatively associated with COVID-19 incidence.

\section{Discussion}

This study explores the association between local meteorological factors and local-level COVID-19 transmission in Bangladesh accounting several potential confounding factors. Overall, the quasi-Poisson model's findings and arealaggregated findings suggest that daily COVID-19 incidence was positively associated with mean temperature, relative humidity, and wind speed. A negative association is observed between daily COVID-19 incidence and precipitation.

A significant and weak correlation between meteorological variables and local-level COVID-19 incidence is observed. The weak correlation could be attributed to epidemic progression, longer time series data, and the nonlinear nature of COVID-19 counts. However, the quasi-Poisson model exhibited a strong positive association between COVID-19 and 
Table 4 The association between daily COVID-19 incidence and meteorological variables

\begin{tabular}{|c|c|c|c|}
\hline Districts & Coefficient & $\mathrm{RR}$ & $95 \% \mathrm{CI}$ \\
\hline \multicolumn{4}{|l|}{ Dhaka city } \\
\hline Temperature & $0.129 * * *$ & 1.128 & $1.127-1.150$ \\
\hline Relative humidity & 0.016 & 1.016 & $1.014-1.019$ \\
\hline Precipitation & 0.002 & 1.00 & $1.001-1.005$ \\
\hline Wind speed & $0.060 * *$ & 1.06 & $1.056-1.068$ \\
\hline \multicolumn{4}{|l|}{ Chattogram } \\
\hline Temperature & $0.669 * * *$ & 1.952 & $1.885-2.023$ \\
\hline Relative humidity & $0.112 *$ & 1.118 & $1.105-1.133$ \\
\hline Precipitation & $0.033^{* *}$ & 1.033 & $1.030-1.036$ \\
\hline Wind speed & 0.123 & 1.131 & $1.109-1.153$ \\
\hline \multicolumn{4}{|l|}{ Narayanganj } \\
\hline Temperature & -0.223 & 0.799 & $0.773-0.826$ \\
\hline Relative humidity & $-0.108 * *$ & 0.897 & $0.888-0.905$ \\
\hline Precipitation & 0.029 & 1.029 & $1.022-1.036$ \\
\hline Wind speed & 0.108 & 1.114 & $1.09-1.138$ \\
\hline \multicolumn{4}{|l|}{ Gazipur } \\
\hline Temperature & 0.049 & 1.050 & $1.007-1.096$ \\
\hline Relative humidity & -0.019 & 0.980 & $0.970-0.990$ \\
\hline Precipitation & 0.011 & 1.011 & $1.004-1.018$ \\
\hline Wind speed & 0.097 & 1.102 & $1.076-1.129$ \\
\hline \multicolumn{4}{|l|}{ Sylhet } \\
\hline Temperature & $0.122 * *$ & 1.129 & $1.084-1.177$ \\
\hline Relative humidity & $0.095 * * *$ & 1.099 & $1.082-1.1185$ \\
\hline Precipitation & $-0.014 * * *$ & 0.985 & $0.982-0.989$ \\
\hline Wind speed & $0.202 * * *$ & 1.224 & $1.181-1.269$ \\
\hline \multicolumn{4}{|l|}{ Rangpur } \\
\hline Temperature & $0.257 * * *$ & 1.293 & $1.225-1.366$ \\
\hline Relative humidity & 0.001 & 1.00 & $0.983-1.019$ \\
\hline Precipitation & -0.002 & 0.997 & $0.992-1.003$ \\
\hline Wind speed & 0.038 & 1.039 & $0.988-1.093$ \\
\hline \multicolumn{4}{|l|}{ Rajshahi } \\
\hline Temperature & $0.857 * * *$ & 2.356 & $2.153-2.580$ \\
\hline Relative humidity & $0.206^{* * *}$ & 1.229 & $1.200-1.258$ \\
\hline Precipitation & $0.043 * * *$ & 1.044 & $1.037-1.0512$ \\
\hline Wind speed & 0.029 & 1.030 & $0.988-1.074$ \\
\hline \multicolumn{4}{|l|}{ Bogura } \\
\hline Temperature & $0.422 * * *$ & 1.525 & $1.456-1.5983$ \\
\hline Relative humidity & 0.008 & 1.008 & $0.996-1.021$ \\
\hline Precipitation & $0.046^{* * *}$ & 1.047 & $1.042-1.052$ \\
\hline Wind speed & $0.184 * * *$ & 1.202 & $1.156-1.252$ \\
\hline \multicolumn{4}{|l|}{ Khulna } \\
\hline Temperature & $0.728 * * *$ & 2.072 & $1.911-2.245$ \\
\hline Relative humidity & $0.185^{* * *}$ & 1.203 & $1.182-1.225$ \\
\hline Precipitation & $-0.037 *$ & 0.963 & $0.955-0.971$ \\
\hline Wind speed & $0.188 * *$ & 1.206 & $1.173-1.241$ \\
\hline \multicolumn{4}{|l|}{ Areal-aggregated } \\
\hline Temperature & $0.193 * * *$ & 1.2222 & $1.214-1.232$ \\
\hline Relative humidity & $0.020 * *$ & 1.020 & $1.0253-1.029$ \\
\hline Precipitation & $-0.012 * * *$ & 0.987 & $0.989-0.990$ \\
\hline Wind speed & $0.095^{* * *}$ & 1.093 & $1.0832-1.090$ \\
\hline
\end{tabular}

$* * *, * *$, and $*$ indicate significance level at $1 \%, 5 \%$, and $10 \%$ respectively

temperature for all selected areas (Dhaka, Chattogram, Sylhet, Rangpur, Bogura, Rajshahi, Khulna). A higher number of cases were reported in these areas, which experienced relatively higher temperatures $28-31{ }^{\circ} \mathrm{C}$ (Fig. 3a) during the period of observation. A positive association between COVID-19 and humidity was found for the selected areas (Chattogram,
Khulna, Rajshahi). A higher number of cases were reported in these areas with high humidity $80-92 \%$ (Fig. 3b). Precipitation was positively associated with COVID-19 transmission for the selected areas (Chattogram, Rajshahi, Bogura). A higher number of cases were reported in these areas with more than $30 \mathrm{~mm}$ of daily precipitation (Fig. 3c). On the contrary, precipitation was negatively associated with COVID-19 for the selected areas (Sylhet and Khulna). A higher number of cases were reported in these areas with less than $30 \mathrm{~mm}$ of daily precipitation (Fig. 3c). Wind speed was positively associated with COVID-19 incidence for the selected locations (Dhaka, Sylhet, Khulna, and Bogura). A higher number of cases were reported in these areas with $2-6 \mathrm{~km} / \mathrm{h}$ of daily wind speed (Fig. 3d).

Several studies have reported that low temperatures likely to favor the transmission of SARS-CoV-2 in China (Liu et al. 2020; Yongjian et al. 2020). On the contrary, Xie and Zhu (2020) found a positive linear association between mean temperature and daily COVID-19 incidence at $3{ }^{\circ} \mathrm{C}$ threshold. Still, no evidence was found that COVID-19 incidence could decline due to warm weather in China. In contrast to these findings, however, there was no association between COVID-19 and temperature in Wuhan, China (Iqbal et al. 2020).

However, the current study has found a positive effect of temperature on COVID-19 transmission in Bangladesh; the finding is in line with previous literature and supports the findings of Bashir et al. (2020), Pedrosa (2020), and Tosepu et al. (2020) in India (Kafieh et al. 2020) and Bangladesh (Islam et al. 2020a, b). The positive effect of humidity on COVID-19 transmission in Bangladesh is in line with previous literature on a worldwide study (Sajadi et al. 2020), in China (Luo et al. 2020b), in India (Goswami et al. 2020), and in Bangladesh (Islam et al. 2020a, b). The positive effect of wind speed on COVID-19 transmission in this study is in line with previous literature on India and worldwide (Sarkodie and Owusu 2020) and in Bangladesh (Islam et al. 2020a, b).

The observations demonstrated that low relative humidity increases the viability of influenza in the aerosol, which favors the transmission of the influenza virus (Brankston et al. 2007) and impairs the innate antiviral defense of the host (Kudo et al. 2019). Moreover, the low temperature had the same effect on influenza as humidity (Lowen et al. 2007). Similar to influenza, respiratory diseases SARS-CoV and MERS-CoV were more likely to remain viable in low temperature and humidity (Casanova et al. 2010; Chan et al. 2011; Gardner et al. 2019). Chan et al. (2011) reported that higher temperatures (e.g., $38{ }^{\circ} \mathrm{C}$ ) and higher humidity ( $\left.>95 \% \mathrm{RH}\right)$ had been found to reduce the SARS-CoV-1 virus viability significantly. Several studies have found the wind speed and precipitation were positively associated with influenza transmission (GomezBarroso et al. 2017; Lopez et al. 2014; Mahamat et al. 2013). However, based on an experimental study on the 
influenza virus, Lowen et al. (2008) have demonstrated that temperature more than $30^{\circ} \mathrm{C}$ blocks aerosol transmission, but not contact transmission. The finding implies that contact or short-range transmission of the influenza virus was dominant in tropical and subtropical regions.

Viruses can be transmitted through the air via droplets or aerosols generated during coughing, sneezing, talking, singing, or breathing (da Silva et al. 2020; Jones and Brosseau 2015). Various experimental studies have shown that high temperatures and relative humidity could affect SARS-CoV2 viability. However, considering the increasingly high number of cases in the south of the USA, Brazil, India, and Bangladesh, where high temperatures and humidity have been observed, does not support the effect of these conditions (da Silva et al. 2020).

SARS-CoV-1 can transmit through respiratory droplets. As it shares genetic similarities with SARS-CoV-2, it is assumed that SARS-CoV-2 too can transmit through respiratory droplets. However, the SARS-CoV-2 can be transmitted human to human over various routes, by droplets, aerosol, and fomites (Wei et al. 2020). However, airborne transmission via aerosols is highly virulent and dominant (Zhang et al. 2020). The viability and infectivity of viruses in the aerosol are influenced by environmental stress such as temperature and humidity (Jayaweera et al. 2020). The SARS-CoV-2 can remain viable in an aerosol form $(<5 \mu \mathrm{m})$ for $3 \mathrm{~h}$, while it showed more viability in droplets form $(>5 \mu \mathrm{m})$ on plastic and stainless steel, copper, cardboard, and glass up to $72 \mathrm{~h}$ (Van Doremalen et al. 2020).

Dbouk and Drikakis (2020a), creating a computational fluid dynamics simulation, exemplified wind speed's role in the airborne transmission of SARS-CoV-2. The result revealed that, the respiratory droplets can travel up to $6 \mathrm{~m}$ at wind speeds ranging from 4 to $15 \mathrm{~km} / \mathrm{h}$, implying that $2 \mathrm{~m}$ social distancing may not be effective. In another recent study, Dbouk and Drikakis (2020b) investigated the effects of relative humidity, temperature, and wind speed on the transport and viability of SARS-CoV-2 in a cloud of airborne droplets. The result indicated that the viability of SARS-CoV-2 is reduced substantially when both high temperatures and low relative humidity occur due to the lower evaporation rate of the saliva-contaminated droplets. Moreover, Dbouk and Drikakis (2020b) have observed that the droplet cloud's travel distance and concentration remained significant at any temperature if the relative humidity remains high. The findings of Dbouk and Drikakis (2020b) offer a reasonable explanation why Bangladesh has seen a peak of COVID-19 cases from June to July when Bangladesh has experienced both high temperatures and high relative humidity (Table 2).

This finding is also supported by Luo et al. (2020a), who reported that SARS-CoV-2 was transmitted in high temperature and high humid environment of the public bath center in China. This observation implies that SARS-CoV-2 can remain viable in such conditions and has shown no weakening in high temperatures and humidity. Based on the climate-dependent epidemic model, Baker et al. (2020) have suggested that SARS-CoV-2 outbreak is likely to persist in a warm, humid environment without adequate control measures. Furthermore, the warmer summer weather will not limit the transmission of SARS-CoV-2 substantially, which has been observed in Bangladesh.

Dhaka city is the most air polluted country in the world (The Daily Star 2019). Coccia (2020) has reported that cities with higher concentrations of air pollutants were associated with low wind speeds $(<9.8 \mathrm{~km} / \mathrm{h})$ in Italy. This may promote a longer permanence of viral particles in polluted air, favoring an indirect means of diffusion of SARS-CoV-2. The finding of Coccia (2020) is similar to this study as the heat map suggests most of the cases were reported with wind speed ranging 0-9 km/h in Dhaka city (Fig. 3d). Thus, it can be hypothesized that high air pollutants and low wind speed might significantly affect COVID-19 transmission in Dhaka city. At community level, transmission of COVID-19 can be modulated by local policies such as social distancing and the number of susceptible individuals. Taking human mobility as a proxy for social distancing, Kraemer et al. (2020) found that intervention measures reduced SARS-CoV-2 transmission in Wuhan. In addition, strict local control measures (social isolations and hygiene) shared a significant proportion in controlling SARS-CoV-2 transmission. Rubin et al. (2020) showed social distancing was substantially associated with decreased SARS-CoV-2 transmission in the USA. A similar finding was also pronounced in the UK (Hadjidemetriou et al. 2020).

Overall, based on areal-aggregated results, a negative effect of precipitation on daily COVID-19 incidence is found. This finding can be attributed to the hypothesis that people stayed at home when it is rainy (Menebo 2020). However, local-level precipitation (Chattogram, Rajshahi, Bogura) is positively associated with local-level COVID-19 transmission. This positive effect of precipitation on local-level COVID-19 transmission is in line with previous literature and supports the findings (Méndez-Arriaga 2020; Wei et al. 2020). Moreover, it has been found that increased rainfall may favor SARSCoV-2 viability by decreasing the evaporation of droplets, making them readily settle on surfaces (Lowen et al. 2007; Lu et al. 2020; Wei et al. 2020).

Taken all together, the overwhelming studies (Baker et al. 2020; Dbouk and Drikakis 2020b; Feng et al. 2020; Luo et al. 2020a; Zhao et al. 2020) suggest that SARS-CoV-2 can remain viable in high temperatures and high humid conditions. Bu et al. (2020) concluded that the optimal temperature and humidity ranges for SARS-CoV-2 survival and transmission are $13-19{ }^{\circ} \mathrm{C}$ and $50-70 \%$, respectively. Therefore, Bangladesh should be vigilant in the upcoming winter season, when the most suitable condition for transmission of SARSCoV-2 may persist. Furthermore, as discussed above, the 
COVID-19 outbreak might continue until the next warmer summer if the entire population does not get vaccinated or immunized. Overall, we find no supporting evidence that warmer temperatures and humidity curbed the COVID-19 epidemic in Bangladesh.

The current study has some limitations. The transmission of COVID-19 can be confounded by daily performed tests, air pollution, number of imported cases, population immunity, population migration, human mobility, social behavior, economic and cultural conditions, and these factors were not considered in the study. Moreover, one of our study's fundamental limitations is that our observations are based on outdoor weather environment data. However, the indoor environments can influence SARS-CoV-2 transmission very differently. Future studies should include these factors when assessing the association of meteorological variables and COVID-19 in Bangladesh.

\section{Conclusion}

The present study aimed to explore how meteorological parameters impact COVID-19 transmission using a longer time series data. The present study utilizes heat map, correlation, and quasi-Poisson regression model to explore the effects of meteorological parameters on COVID-19 incidence across nine districts in Bangladesh. Findings illustrate that meteorological variables are substantially associated with local COVID-19 transmission in Bangladesh. For the period selected in the study, areal-aggregated results suggest that the COVID-19 transmission was favored by the coupling influence of mean temperature, relative humidity, and wind speed. Meanwhile, a negative association was also observed between COVID-19 incidence and precipitation. The findings also suggest that meteorological variables will mediate future COVID19 transmission in Bangladesh. However, it does not mean that meteorological factors control the transmission solely as mentioned in the previous section. The key strength of the study is its long durational observation and has considered several confounding factors. The present study has considered only four meteorological variables. Future research should include more variables to enhance accuracy. The findings may help to understand how seasonality may impact the transmission of COVID-19 in Bangladesh. Thus, it is imperative to focus on developing urgent mechanisms and policies to tackle the COVID-19 outbreak in Bangladesh considering all influencing factors including the meteorological issues. Moreover, the findings of this study might be useful for future studies in other countries with similar climate conditions and population density.

Acknowledgments The authors are thankful to the Institute of Epidemiology, Disease Control and Research (IEDCR), Bangladesh,
National Oceanic and Atmospheric Administration (NOAA), Bangladesh Bureau of Statistics (BBS), Daily Newspapers, and all other data sources for providing data for this study.

Author contributions Conceptualization and approval: Hridoy A.E., Rahman M.A.; methodology: Hridoy A.E., Rahman M.A.; software: Hridoy A.E.; analysis: Hridoy A.E., Tusher S.M.S.H.; data curation: Tusher S.M.S.H.; validation: Hridoy A.E.; draft preparation: Hridoy A.E., Mohiman M.A., Nowraj S.Z.A.; visualization: Hridoy A.E.; mapping: Nowraj S.Z.A.; review and editing: Rahman M.A., Mohiman M.A.; supervision: Rahman M.A.

\section{Compliance with ethical standards}

Conflict of interest The authors declare that they have no conflict of interest.

\section{References}

Baker RE, Yang W, Vecchi GA, Metcalf CJE, Grenfell BT (2020) Susceptible supply limits the role of climate in the early SARSCoV-2 pandemic. Science 369(6501):315-319

Bashir MF, Ma B, Komal B, Bashir MA, Tan D, Bashir M (2020) Correlation between climate indicators and COVID-19 pandemic in New York, USA. Sci Total Environ 728:138835

BBS (2011) Bangladesh population census and housing census, 2011, National Volume, Bangladesh Bureau of Statistics, Ministry of Planning, Government of Bangladesh

Brankston G, Gitterman L, Hirji Z, Lemieux C, Gardam M (2007) Transmission of influenza A in human beings. Lancet Infect Dis 7: 257-265

Briz-Redón Á, Serrano-Aroca Á (2020) The effect of climate on the spread of the COVID-19 pandemic: a review of findings, and statistical and modelling techniques. Prog Phys Geogr 44(18): 0309133320946302

Bu J, Peng DD, Xiao H, Yue Q, Han Y, Lin Y, Hu G, Chen J (2020) Analysis of meteorological conditions and prediction of epidemic trend of 2019-nCoV infection in 2020. medRxiv. https://doi.org/10. 1101/2020.02.13.20022715

Cai Q-C, Lu J, Xu QF, Guo Q, Xu DZ, Sun QW, Yang H, Zhao GM, Jiang QW (2007) Influence of meteorological factors and air pollution on the outbreak of severe acute respiratory syndrome. Public Health 121:258-265

Cao C, Chen W, Zheng S, Zhao J, Wang J, Cao W (2016) Analysis of spatiotemporal characteristics of pandemic SARS spread in mainland China. Biomed Res Int 2016:7247983

Casanova LM, Jeon S, Rutala WA, Weber DJ, Sobsey MD (2010) Effects of air temperature and relative humidity on coronavirus survival on surfaces. Appl Environ Microbiol 76:2712-2717

Chan K, Peiris J, Lam S, Poon L, Yuen K, Seto W (2011) The effects of temperature and relative humidity on the viability of the SARS coronavirus. Adv Virol 2011:734690

Coccia M (2020) How do low wind speeds and high levels of air pollution support the spread of COVID-19? Atmos Pollut Res. https://doi.org/ 10.1016/j.apr.2020.10.002

da Silva PG, Nascimento MSJ, Soares RR, Sousa SI, Mesquita JR (2020) Airborne spread of infectious SARS-CoV-2: moving forward using lessons from SARS-CoV and MERS-CoV. Sci Total Environ 8: 142802

Dalziel BD, Kissler S, Gog JR, Viboud C, Bjørnstad ON, Metcalf CJE, Grenfell BT (2018) Urbanization and humidity shape the intensity of influenza epidemics in US cities. Science 362:75-79 
Davis RE, Dougherty E, McArthur C, Huang QS, Baker MG (2016) Cold, dry air is associated with influenza and pneumonia mortality in Auckland, New Zealand. Influenza Other Respir Viruses 10:310 313

Dbouk T, Drikakis D (2020a) On coughing and airborne droplet transmission to humans. Phys Fluids 32:053310

Dbouk T, Drikakis D (2020b) Weather impact on airborne coronavirus survival. Phys Fluids 32:093312

Feng Y, Marchal T, Sperry T, Yi H (2020) Influence of wind and relative humidity on the social distancing effectiveness to prevent COVID19 airborne transmission: a numerical study. J Aerosol Sci 147: 105585

Gardner EG, Kelton D, Poljak Z, Van Kerkhove M, Von Dobschuetz S, Greer AL (2019) A case-crossover analysis of the impact of weather on primary cases of Middle East respiratory syndrome. BMC Infect Dis 19:1-10

Gomez-Barroso D, León-Gómez I, Delgado-Sanz C, Larrauri A (2017) Climatic factors and influenza transmission, Spain, 2010-2015. Int J Environ Res Public Health 14:1469

Goswami K, Bharali S, Hazarika J (2020) Projections for COVID-19 pandemic in India and effect of temperature and humidity. Diabetes Metab Syndr 14(5):801-805

Guo XJ, Zhang H, Zeng YP (2020) Transmissibility of COVID-19 in 11 major cities in China and its association with temperature and humidity in Beijing, Shanghai, Guangzhou, and Chengdu. Infect Dis Poverty 9(1). https://doi.org/10.1186/s40249-020-00708-0

Hadjidemetriou GM, Sasidharan M, Kouyialis G, Parlikad AK (2020) The impact of government measures and human mobility trend on COVID-19 related deaths in the UK. Transp Res Interdisc Perspectives 6:100167

Haque SE, Rahman M (2020) Association between temperature, humidity, and COVID-19 outbreaks in Bangladesh. Environ Sci Pol 114: 253-255

Hasan NA, Siddik MS (2020) Possible Role of Meteorological Variables in COVID- 19 Spread: A Case Study from a Subtropical Monsoon Country, Bangladesh. Preprints 2020060347. https://doi.org/10. 20944/preprints202006.0347.v1

Hemmes J, Winkler K, Kool S (1960) Virus survival as a seasonal factor in influenza and poliomyelitis. Nature 188:430-431

Hoffmann JP (2004) Generalized linear models: an applied approach. Boston: Pearson A and B. http://catalog.hathitrust.org/api/volumes/ oclc/51963419.html

Imai C, Hashizume M (2014) Systematic review on methodology: time series regression analysis for environmental factors and infectious diseases. Trop Med Health 43(1):1-9

Imai C, Armstrong B, Chalabi Z, Mangtani P, Hashizume M (2015) Time series regression model for infectious disease and weather. Environ Res 142:319-327

Iqbal N, Fareed Z, Shahzad F, He X, Shahzad U, Lina M (2020) Nexus between COVID-19, temperature and exchange rate in Wuhan City: new findings from partial and multiple wavelet coherence. Sci Total Environ 729:138916

Islam ARMT, Hasanuzzaman M, Azad MAK, Salam R, Toshi FZ, Khan MSI, Alam GM and Ibrahim SM (2020a) Effect of meteorological factors on COVID-19 cases in Bangladesh. Environ Dev Sustain 8: $1-24$

Islam ARMT, Hasanuzzaman M, Shammi M, Salam R, Bodrud-Doza M, Rahman MM, Mannan MA, Huq S (2020b) Are meteorological factors enhancing COVID-19 transmission in Bangladesh? Novel findings from a compound Poisson generalized linear modeling approach. Environ Sci and Pollut Res:1-14

Jahangiri M, Jahangiri M, Najafgholipour M (2020) The sensitivity and specificity analyses of ambient temperature and population size on the transmission rate of the novel coronavirus (COVID-19) in different provinces of Iran. Sci Total Environ 728:138872
Jayaweera M, Perera H, Gunawardana B, Manatunge J (2020) Transmission of COVID-19 virus by droplets and aerosols: a critical review on the unresolved dichotomy. Environ Res 188:109819

Jones RM, Brosseau LM (2015) Aerosol transmission of infectious disease. J Occup Environ Med 57:501-508

Joshi YP, Kim E-H, Kim J-H, Kim H, Cheong H-K (2016) Associations between meteorological factors and aseptic meningitis in six metropolitan provinces of the republic of Korea. Int J Environ Res Public Health 13:1193

Kafieh R, Arian R, Saeedizadeh N, Minaee S, Yadav SK, Vaezi A, Rezaei N, Javanmard SH (2020) COVID-19 in Iran: a deeper look into the future. medRxiv. https://doi.org/10.1101/2020.04.24. 20078477

Kraemer MU, Yang CH, Gutierrez B, Wu CH, Klein B, Pigott DM, Du Plessis L, Faria NR, Li R, Hanage WP, Brownstein JS (2020) The effect of human mobility and control measures on the COVID-19 epidemic in China. Science 368:493-497

Kudo E, Song E, Yockey LJ, Rakib T, Wong PW, Homer RJ, Iwasaki A (2019) Low ambient humidity impairs barrier function and innate resistance against influenza infection. Proc Natl Acad Sci 116: 10905-10910

Lin H, Zou H, Wang Q, Liu C, Lang L, Hou X, Li Z (2013) Short-term effect of El Nino-Southern Oscillation on pediatric hand, foot and mouth disease in Shenzhen, China. PLoS One 8:e65585. https://doi. org/10.1371/journal.pone.0065585

Liu J, Zhou J, Yao J, Zhang X, Li L, Xu X, He X, Wang B, Fu S, Niu T, Yan J (2020) Impact of meteorological factors on the COVID-19 transmission: a multi-city study in China. Sci Total Environ 726: 138513

Long JS (1997) Regression models for categorical and limited dependent variables: advanced quantitative techniques in the social sciences: 7 : 219. Sage Publications, Thousand Oaks

Lopez D, Gunasekaran M, Murugan BS, Kaur H, Abbas KM (2014) Spatial big data analytics of influenza epidemic in Vellore, India. 796In: 2014 IEEE international conference on big data (Big Data). IEEE, pp 19 -24. https://doi.org/10.1109/BigData.2014.7004422

Lowen AC, Mubareka S, Steel J, Palese P (2007) Influenza virus transmission is dependent on relative humidity and temperature. PLoS Pathog 3:e151

Lowen AC, Steel J, Mubareka S, Palese P (2008) High temperature (30 C) blocks aerosol but not contact transmission of influenza virus. J Virol 82:5650-5652

Lu C-w, Liu X-F, Jia Z-F (2020) 2019-nCoV transmission through the ocular surface must not be ignored. Lancet 395:e39

Luo C, Yao L, Zhang L, Yao M, Chen X, Wang Q, Shen H (2020a) Possible transmission of severe acute respiratory syndrome coronavirus 2 (SARS-CoV-2) in a public bath center in Huai'an, Jiangsu Province, China. JAMA Netw Open 3:e204583-e204583

Luo W, Majumder MS, Liu D, Poirier C, Mandl KD, Lipsitch M, Santillana M (2020b) The role of absolute humidity on transmission rates of the COVID-19 outbreak. medRxiv. https://doi.org/10.1101/ 2020.02.12.20022467

Mahamat A, Dussart P, Bouix A, Carvalho L, Eltges F, Matheus S, Miller MA, Quenel P, Viboud C (2013) Climatic drivers of seasonal influenza epidemics in French Guiana, 2006-2010. J Infect 67:141-147

Méndez-Arriaga F (2020) The temperature and regional climate effects on communitarian COVID-19 contagion in Mexico throughout phase 1. Sci Total Environ 735:139560. https://doi.org/10.1016/j. scitotenv.2020.139560

Menebo MM (2020) Temperature and precipitation associate with Covid19 new daily cases: a correlation study between weather and Covid19 pandemic in Oslo, Norway. Sci Total Environ 737:139659. https://doi.org/10.1016/j.scitotenv.2020.139659

Mofijur M, Fattah IMR, Islam AS, Uddin MN, Rahman SA, Chowdhury MA, Alam MA, Uddin MA (2020) Relationship between Weather Variables and New Daily COVID-19 Cases in Dhaka, 
Bangladesh. Sustainability 12(20):8319. https://doi.org/10.3390/ su12208319

New Age (2020) 84,000 COVID-19 patients missing from Bangladesh database. https://www.newagebd.net/article/115919/84000-covid19-patients-missing-from-bangladesh-database. Accessed 12 Oct 2020

Oliveiros B, Caramelo L, Ferreira NC, Caramelo F (2020) Role of temperature and humidity in the modulation of the doubling time of COVID-19 cases. medRxiv. https://doi.org/10.1101/2020.03.05. 20031872

O'Reilly KM, Auzenbergs M, Jafari Y, Liu Y, Flasche S, Lowe R (2020) Effective transmission across the globe: the role of climate in COVID-19 mitigation strategies. Lancet Planet Health 4:e172

Pedrosa RHL (2020) The dynamics of Covid-19: weather, demographics and infection timeline. medRxiv. https://doi.org/10.1101/2020.04. 21.20074450

Poirier C, Luo W, Majumder MS, Liu D, Mandl KD, Mooring TA, Santillana M (2020) The role of environmental factors on transmission rates of the COVID-19 outbreak: an initial assessment in two spatial scales. Sci Rep 10:17002. https://doi.org/10.1038/s41598020-74089-7

Qin J, You C, Lin Q, Hu T, Yu S, Zhou XH (2020) Estimation of incubation period distribution of COVID-19 using disease onset forward time: A novel cross-sectional and forward follow-up study. Sci Adv 6(33). https://doi.org/10.1126/sciadv.abc1202

Rahman MS, Azad MAK, Hasanuzzaman M, Salam R, Islam AR, Rahman MM, Hoque MM (2020) How air quality and COVID-19 transmission change under different lockdown scenarios? A case from Dhaka city, Bangladesh. Sci Total Environ 762:143161. https://doi.org/10.1016/j.scitotenv.2020.143161

Rashid HE (2019) Geography of Bangladesh. Routledge, Abingdon

Rendana M (2020) Impact of the wind conditions on COVID-19 pandemic: a new insight for direction of the spread of the virus. Urban Clim 34:100680

Rothman KJ, Greenland S, Lash TL (2008) Modern epidemiology. Philadelphia: Wolters Kluwer Health/Lippincott Williams \& Wilkins. http://www.r2library.com/public/ResourceDetail.aspx? authCheck=true\&resid $=2127$

Rubin D, Huang J, Fisher BT, Gasparrini A, Tam V, Song L, Wang X, Kaufman J, Fitzpatrick K, Jain A, Griffis H. (2020) Association of social distancing, population density, and temperature with the instantaneous reproduction number of SARS-CoV-2 in counties across the United States. JAMA Netw Open 3:e2016099-e2016099

Runkle JD, Sugg MM, Leeper RD, Rao Y, Mathews JL, Rennie JJ (2020) Short-term effects of weather parameters on COVID-19 morbidity in select US cities. Sci Total Environ 740:140093

Sajadi MM, Habibzadeh P, Vintzileos A, Shokouhi S, Miralles-Wilhelm F, Amoroso A (2020) Temperature, humidity, and latitude analysis to estimate potential spread and seasonality of coronavirus disease 2019 (COVID-19). JAMA Netw Open 3:e2011834-e2011834

Sarkodie SA, Owusu PA (2020) Impact of meteorological factors on COVID-19 pandemic: evidence from top 20 countries with confirmed cases. Environ Res 191:110101

Shaman J, Kohn M (2009) Absolute humidity modulates influenza survival, transmission, and seasonality. Proc Natl Acad Sci 106:32433248

Shammi M, Bodrud-Doza M, Towfiqul Islam AR, Rahman MM (2020a) COVID-19 pandemic, socioeconomic crisis and human stress in resource-limited settings: A case from Bangladesh. Heliyon. https://doi.org/10.1016/j.heliyon.2020.e04063
Shammi M, Bodrud-Doza M, Islam ARMT, Rahman MM (2020b) Strategic assessment of COVID-19 pandemic in Bangladesh: comparative lockdown scenario analysis, public perception, and management for sustainability. Enviro Dev Sustain 18:1-44

Shi $\mathrm{P}$ et al (2020) The impact of temperature and absolute humidity on the coronavirus disease 2019 (COVID-19) outbreak - evidence from China. medRxiv. https://doi.org/10.1101/2020.03.22.20038919

Tan J, Mu L, Huang J, Yu S, Chen B, Yin J (2005) An initial investigation of the association between the SARS outbreak and weather: with the view of the environmental temperature and its variation. J Epidemiol Community Health 59:186-192

The Daily Star (2019) Dhaka now most air polluted city in the world: Minister. https://www.thedailystar.net/environment/dhaka-most-airpolluted-city-in-the-world-1831786.

Tosepu R, Gunawan J, Effendy DS, Lestari H, Bahar H, Asfian P (2020) Correlation between weather and Covid-19 pandemic in Jakarta, Indonesia. Sci Total Environ 725:138436

Van Doremalen N, Bushmaker T, Morris D, Holbrook M, Gamble A, Williamson B, Lloyd-Smith JO (2020) Aerosol and surface stability of SARS-CoV-2 as compared with SARS-CoV-1. N Engl J Med 382(16):1564-1567

Wang J, Du G (2020) COVID-19 may transmit through aerosol. Ir J Med Sci (1971-):1-2

Wang M, Jiang A, Gong L, Luo L, Guo W, Li C, Zheng J, Li C, Yang B, Zeng J, Chen Y (2020) Temperature significant change COVID-19 Transmission in 429 cities. MedRxiv

Wei JT, Liu YX, Zhu YC, Qian J, Ye RZ, Li CY, Ji XK, Li HK, Qi C, Wang Y, Yang F (2020) Impacts of transportation and meteorological factors on the transmission of COVID-19. Int J Hyg Environ Health 230:113610

WHO (2020) Situation report-51. https://www.who.int/emergencies/ diseases/novel-coronavirus-2019/situation-reports. Accessed Aug 04, 2020

Xie J, Zhu Y (2020) Association between ambient temperature and COVID-19 infection in 122 cities from China. Sci Total Environ 724:138201

Yongjian Z, Jingu X, Fengming H, Liqing C (2020) Association between short-term exposure to air pollution and COVID-19 infection: evidence from China. Sci Total Environ 727:138704

$\mathrm{Yu} X$ (2020) Impact of mitigating interventions and temperature on the instantaneous reproduction number in the COVID-19 pandemic among 30 US metropolitan areas. One Health. https://doi.org/10. 1016/j.onehlt.2020.100160

Yuan S, Jiang S, Li Z-L (2020) Do humidity and temperature impact the spread of the novel coronavirus? Front Public Health 8:240

Zaitchik BF, Sweijd N, Shumake-Guillemot J, Morse A, Gordon C, Marty A, Trtanj J, Luterbacher J, Botai J, Behera S, Lu Y (2020) A framework for research linking weather, climate, and COVID-19. Nature Commun 11:1-3

Zhang Z, Xue T, Jin X (2020) Effects of meteorological conditions and air pollution on COVID-19 transmission: evidence from 219 Chinese cities. Sci Total Environ 741:140244

Zhao L, Qi Y, Luzzatto-Fegiz P, Cui Y, Zhu Y (2020) COVID-19: Effects of environmental conditions on the propagation of respiratory droplets. Nano Letters 20:7744-7750. https://doi.org/10.1021/ acs.nanolett.0c03331

Publisher's note Springer Nature remains neutral with regard to jurisdictional claims in published maps and institutional affiliations. 